\title{
Intermediate-term outcomes of the arterial switch operation for transposition of great arteries in neonates: Alive but well?
}

Darren H. Freed, MD, PhD, ${ }^{a}$ Charlene M. T. Robertson, MD, ${ }^{b, c}$ Reginald S. Sauve, MD, ${ }^{d}$ Ari R. Joffe, MD, ${ }^{b}$ Ivan M. Rebeyka, MD, ${ }^{a, b}$ David B. Ross, MD, and John D. Dyck, MD, ${ }^{\mathrm{b}}$ the Western Canadian Complex Pediatric Therapies Project Follow-up Group ${ }^{\mathrm{e}}$

Earn CME credits at http:// cme.ctsnetjournals.org

Supplemental material is available online.
From the Departments of Surgery ${ }^{\mathrm{a}}$ and Pediatrics, ${ }^{\mathrm{b}}$ University of Alberta, Edmonton, Alberta, Canada; Neonatal and Infant Follow-up Clinic, Glenrose Rehabilitation Hospital, Edmonton, Alberta, Canada ${ }^{c}$; Department of Pediatrics, University of Calgary, Calgary, Alberta, Canadad; D. Moddemann, Winnipeg, Manitoba; P. Blakley, Saskatoon, Saskatchewan; W. D. Reid, Regina, Saskatchewan. ${ }^{\mathrm{e}}$

Financial support was initially provided by the Glenrose Rehabilitation Hospital Research Trust Fund with ongoing funding from the Registry and Follow-up of Complex Pediatric Therapies Project, Alberta Health and Wellness.

Received for publication Jan 26, 2006; accepted for publication May 3, 2006.

Address for reprints: Charlene M. T. Robertson, MD, Room 242, GlenEast, Glenrose Rehabilitation Hospital, 10230-111 Avenue, Edmonton, Alberta T5G 0B7 (E-mail: croberts@cha.ab.ca).

J Thorac Cardiovasc Surg 2006;132:845-52 0022-5223/\$32.00

Copyright (๑) 2006 by The American Association for Thoracic Surgery

doi:10.1016/j.jtcvs.2006.05.046
Objectives: This interprovincial inception cohort study outlines the operative and intermediate outcomes of all neonates at a single institution with a broad referral area who underwent the arterial switch operation for transposition of great arteries, including complex types. Predictors of outcome are explored.

Methods: A total of 88 consecutive neonates underwent the arterial switch operation between 1996 and 2004 with full-flow $(150 \mathrm{mg} / \mathrm{kg} / \mathrm{min})$ cardiopulmonary bypass with selective deep hypothermic circulatory arrest. Overall and event-free survivals were calculated. Health and neurodevelopment (Bayley Scales of Infant Development II) were assessed at 18 to 24 months of age. Univariate and multivariate analyses, sensitivity, and specificity were determined to identify preoperative, intraoperative, and postoperative factors associated with mental and/or motor delay.

Results: There was 1 operative mortality (1.1\%). At the average 4-year follow-up, survival was $98.9 \%$ and freedom from reintervention was $93.2 \%$. Eighty-five children were assessed. Three were excluded because of unrelated postoperative diagnoses. For the remaining 82, mean scores were $89 \pm 17$ (49-118) for mental skills and $92 \pm 15$ (49-125) for motor skills. Anatomic complexity, cardiopulmonary bypass, and deep hypothermic circulatory arrest times were not associated with developmental outcome. Preoperative variables of low gestational age and high preoperative lactate correctly classified $84.1 \%$ of mentally and/or motor-delayed children.

Conclusion: Transposition of great arteries, including complex types, can be corrected with low surgical risk and good intermediate survival; however, neurodevelopmental outcome is a concern. These data suggest that although anatomic complexity may not affect late outcome, there may be potentially modifiable preoperative factors that can be optimized to improve developmental outcomes.

$\mathrm{T}$ The surgical therapy of congenital heart disease and perioperative care in the intensive care unit have made great advances so that the outcomes emphasis for most congenital lesions has shifted from operative results to later outcomes including neurodevelopment. ${ }^{1}$ The surgical treatment of transposition of great arteries (TGA) has evolved significantly over the past 20 years. Presently, TGA, including complex forms, can be repaired using the arterial switch operation (ASO) with a low operative risk in most high-volume centers. ${ }^{2-5}$ On the basis of concerns about the effect of neonatal deep hypothermic circulatory arrest (DHCA) on neurologic development, ${ }^{6}$ studies with patient intake between 1988 and 1992 from the United States ${ }^{7-10}$ have shown the detrimental effect of DHCA on infant psychomotor development, ${ }^{7}$ preschool motor function, ${ }^{8}$ and speech apraxia. ${ }^{8}$ Lowflow cardiopulmonary bypass $(\mathrm{CPB})$ without ${ }^{10}$ or with $\mathrm{DHCA}^{11}$ has shown school- 

Abbreviations and Acronyms
ASO = arterial switch operation
$\mathrm{CPB}=$ cardiopulmonary bypass
DHCA $=$ deep hypothermic circulatory arrest
TGA $=$ transposition of great arteries
ECMO = extracorporeal membrane oxygenation
MDI = Mental Developmental Index
PDI $\quad=$ Psychomotor Development Index
$\mathrm{SD} \quad=$ standard deviation
VSD $=$ ventricular septal defect

ing to the complexity of their cardiac anomalies: Group A, simple TGA with intact ventricular septum $(\mathrm{n}=52)$; Group B, TGA with ventricular septal defect (VSD) $(\mathrm{n}=22)$; and Group C, complex TGA $(\mathrm{n}=14)$. Additional anatomic diagnoses in Group $\mathrm{C}$ included double outlet right ventricle (Taussig-Bing anomaly), single coronary artery, interrupted aortic arch, aortic coarctation or hypoplastic aortic arch, pulmonary artery anomalies, and left ventricular outflow tract obstruction or aortic stenosis. All surgery was performed at the Stollery Children's Hospital, Edmonton, Alberta, Canada. Surgery was completed with predominantly full-flow $\mathrm{CPB}$ and moderate hypothermia with selective use of DHCA. A modified $\mathrm{pH}$-stat strategy was used for cooling.

Acute care variables recorded prospectively at our institution for the preoperative, early postoperative (24-hour), and later postoperative periods included measures of illness acuity: highest dopamine used; epinephrine used; lowest base deficit, $\mathrm{PAO}_{2}$, and arterial $\mathrm{pH}$; and highest creatinine, plasma lactate, and oxygenation index. Plasma lactate levels were taken as part of clinical management, regularly ordered twice daily, plus obtained routinely with blood gases. The predictive value of plasma lactate at this institution has been published. ${ }^{16}$ Other preoperative variables included out-of-region referral, age at surgery, 5-minute Apgar score, birth gestation and weight, gender, duration of ventilation, antenatal diagnosis, chromosomal abnormality, and socioeconomic index. ${ }^{17}$ Additional variables included overall days of ventilation and hospitalization, need for extracorporeal membrane oxygenation (ECMO) or dialysis, clinical convulsions, cardiopulmonary resuscitation, sepsis, and surgical reintervention. Cranial imaging and electroencephalography testing were not performed except as clinically indicated. Collected intraoperative variables included the following: CPB time with lowest flow for more than 10 minutes and lowest mean arterial pressure for more than 10 minutes on $\mathrm{CPB}$, lowest temperature, crossclamp time, DHCA use, duration of DHCA (not included in CPB time) with lowest temperature during DHCA, and need for repeat $\mathrm{CPB}$.

The 88 children (64\% were boys, $49 \%$ were referred from out of region, and $8 \%$ had an antenatal diagnosis) had a mean gestational age of $38.8 \pm 1.9$ weeks and birth weight of $3.74 \pm 0.62 \mathrm{~kg}$, 5-minute Apgar score of $7.8 \pm 1.4$, age at surgery of $9.9 \pm 6.5$ days, and socioeconomic level of $40.5 \pm 13$. None had microcephaly or known chromosomal abnormality.

At 18 to 24 months of age, a nurse research assistant recorded history of hospitalizations, medication use, and physical measurements. Each child was examined by a pediatrician experienced in neurodevelopmental follow-up, as previously described. ${ }^{12,16}$ Motor or sensory disability was determined if a child had cerebral palsy, ${ }^{18}$ visual impairment (corrected visual acuity in the better eye $<20 / 60$ ), or binaural/bilateral sensorineural hearing loss greater than $40 \mathrm{~dB}$ at any frequency from 250 to $4000 \mathrm{~Hz}$. The Bayley Scales of Infant Development-II ${ }^{19}$ were chosen as the main standardized outcome measure because of their widely accepted use in neonatal follow-up clinics and their separate mental (Mental Developmental Index [MDI]) and motor (Psychomotor Development Index [PDI]) scales. Examiners were experienced pediatric psychologists or psychologic assistants certified for reliability. Developmental indices of less than 70 (2 standard deviation [SD] below mean) indicated mental or motor delay or both. 
TABLE 1. Operative characteristics of 88 neonates undergoing arterial switch operation in relation to complexity of cardiac anomaly: Mean (standard deviation), $\mathrm{n}(\%)$

\begin{tabular}{|c|c|c|c|c|c|c|}
\hline & $\begin{array}{c}\text { Total } \\
\mathrm{n}=\mathbf{8 8}\end{array}$ & $\begin{array}{c}\text { ASO } \\
\mathrm{n}=52\end{array}$ & $\begin{array}{c}\text { ASO/VSD } \\
n=22\end{array}$ & $\begin{array}{c}\text { Complex } \\
\mathrm{n}=14\end{array}$ & $\mathrm{~F}$ or $\chi^{2}$ & $P^{*} \dagger$ \\
\hline CPB (min) & $140.8(69.8)$ & $126.2(64.9)$ & $137.2(26.2)$ & $200.3(101.2) \neq \S$ & 7.139 & .001 \\
\hline Lowest flow for $>10 \mathrm{~min}(\mathrm{~mL} / \mathrm{kg} / \mathrm{min})$ & $105.9(29.5)$ & $106.6(31.5)$ & $109.9(28.5)$ & $97.6(23.3)$ & 0.764 & .469 \\
\hline $\begin{array}{l}\text { Lowest mean arterial pressure for } \\
>10 \mathrm{~min}(\mathrm{~mm} \mathrm{Hg})\end{array}$ & $20.9(6.4)$ & $21.4(5.8)$ & $20.9(5.7)$ & $19.0(2.4)$ & 0.756 & .473 \\
\hline Lowest temperature $\left({ }^{\circ} \mathrm{C}\right)$ & $24.9(2.7)$ & $25.2(2.5)$ & $25.9(2.6)$ & $22.7(2.7) \pm \S$ & 7.371 & .001 \\
\hline Crossclamp time (min) & $69.3(23.7)$ & $58.4(14.5)$ & $74.2(14.6)$ & $103.1(28.2) \ddagger \S$ & 38.28 & $<.001$ \\
\hline DHCA used & $42(47.7 \%)$ & $33(63.5 \%)$ & $3(13.6 \%)$ & $6(42.9 \%)$ & 15.542 & $<.001$ \\
\hline DHCA time (min) (range) $(n=42)$ & $16.8(19.2)(4-75)$ & $12.9(16.4)(5-75)$ & $11.7(9.1)(5-22)$ & $36.5(27.8) \pm \S(4-69)$ & 4.139 & .023 \\
\hline $\begin{array}{l}\text { Lowest temperature }\left({ }^{\circ} \mathrm{C}\right) \text { during } \\
\text { DHCA (range) }(\mathrm{n}=42)\end{array}$ & $23.9(2.8)(18-25)$ & $24.7(2.5)(20-28.1)$ & $20.5(1.3) \ddagger(19-21.5)$ & $21.7(2.5)(18-25)$ & 7.155 & .002 \\
\hline Need for re-CРB & $9(10.2 \%)$ & $2(3.8 \%)$ & $1(4.5 \%)$ & $6(42.9 \%)$ & 19.315 & $<.001$ \\
\hline Reintervention & $6(6.8 \%)$ & $1(1.9 \%)$ & $2(9.1 \%)$ & $3(21.4 \%)$ & 6.844 & .033 \\
\hline
\end{tabular}

ASO, Isolated arterial switch operation; ASO/NSD, arterial switch operation with ventricular septal defect repair; DHCA, deep hypothermic circulatory arrest; $C P B$, cardiopulmonary bypass. After Bonferroni correction, $P$ values of .005 or less remain significant. *0ne-way analysis of variance. $† C h i-s q u a r e$ analysis. $\ddagger$ Significant difference $(P<.01)$ from ASO. §Significant difference from $(P<.01)$ ASO/VSD.

Ethics board approvals in each referring center were obtained before onset of the study. All parents or guardians signed individual consent forms.

\section{Statistics}

Characteristics and outcomes were compared using Yates corrected chi-square analysis, Fisher's exact test, and 1-way analyses of variance with Scheffé multiple comparison. Bonferroni correction for multiple univariate analysis was applied. Kaplan-Meier curves were generated for overall and event-free survival, and were compared with a log-rank test. Independent-samples $t$ test with Levene's test for equality of variances was used to determine differences in operative variables between those with or without developmental delay. Pearson product-moment correlations were used to look for associations between continuous variables. Stepwise multiple regressions were used to look for combinations of variables that predicted outcome. Sensitivity, specificity, and positive and negative predictive values were calculated. SPSS version 12.0 (SPSS Inc, Chicago, Ill) for Windows was used.

\section{Results}

The characteristics of the inception cohort are given in Tables 1 and 2. Of the preoperative variables recorded there were differences between data of children born within the region $(\mathrm{n}=45)$ and children born outside of the region $(\mathrm{n}=$ 43): epinephrine used 11 (24.4\%) vs 3 (7\%), Fisher's exact test (0.024); lowest $\mathrm{PAO}_{2}(28.9 \pm 10.4 \mathrm{~mm} \mathrm{Hg}$ vs $40.2 \pm$ $22.8 \mathrm{~mm} \mathrm{Hg}, t=-2.998, P=.004)$; lowest base deficit $(-6.0 \pm 4.6 \mathrm{mmol} / \mathrm{L}$ vs $-4.8 \pm 4.6 \mathrm{mmol} / \mathrm{L}, t=-2.186$, $P=.032)$; lowest arterial pH (7.26 \pm 0.09 vs $7.34 \pm 0.08$, $t=-3.78, P=.000)$; and highest creatinine $(73.3 \pm 23$ $\mathrm{mmol} / \mathrm{L}$ vs $58 \pm 24.7 \mathrm{mmol} / \mathrm{L}, t=3.013, P=.003)$. There was no difference in the highest plasma lactate (in-born, $4.4 \pm 3.8 \mathrm{mmol} / \mathrm{L}$ vs out-born, $3.7 \pm 4.0 \mathrm{mmol} / \mathrm{L}, t=$ $0.875, P=.384)$. Thirty-one septostomies were performed at our institution; 15 of these were performed in out-ofregion children. Eighteen were performed at other sites. The only preoperative and postoperative difference found among the 3 surgical groups was higher serum creatinine after 24 hours postoperatively for the complex group, $104 \pm$ $49 \mu \mathrm{mol} / \mathrm{L}(1.18 \pm 0.55 \mathrm{mg} / \mathrm{dL})$. The complex group included 3 children who required postoperative ECMO, 4 children who required cardiopulmonary resuscitation, and 5 children who required short-term dialysis.

Three patients had known preoperative neurologic insults that were equally distributed between the groups: cavernous sinus thrombosis, hemorrhagic infarction, and watershed cortical and subcortical infarction. The 1 operative mortality (overall 1.1\%) occurred in the complex Group C. This patient had interrupted aortic arch, right ventricular outflow tract obstruction, and coronary artery anomalies in addition to TGA. He died on postoperative day 22 after cardiopulmonary resuscitation, ECMO, and redo surgery for right ventricular outflow tract obstruction. There were $5(5.7 \%)$ identified postoperative neurologic events ( 3 with intraventricular hemorrhage, 2 with ischemic infarctions) that were equally distributed between the groups. At an average 4-year follow-up (range: 0.6-8.4 years), survival was $98.9 \%$ and freedom from reintervention (surgical or percutaneous) was $93.2 \%$ (Figure E1). Reinterventions addressed stenotic problems on the pulmonary arterial side as well as 2 with superior vena caval complications thought to be related to central venous lines or cannulation sites. 
TABLE 2. Descriptive preoperative and postoperative characteristics of 88 neonates undergoing arterial switch operation: Mean (standard deviation), $\mathrm{n}(\%)$

\begin{tabular}{lccc}
\hline & & \multicolumn{2}{c}{ Postoperative } \\
\cline { 3 - 4 } & Preoperative* & First 24 h & After 24 h \\
\hline Highest level of dopamine used $(\mu \mathrm{g} / \mathrm{kg} / \mathrm{min})$ & $4.5(6.8)$ & $6.8(5.1)$ & $6.1(5.3)$ \\
Epinephrine used & $12(14 \%)$ & $26(30 \%)$ & $29(32 \%)$ \\
Lowest PA0 $(\mathrm{mm} \mathrm{Hg})$ & $36(21)$ & $69(35)$ & $72(21)$ \\
Lowest base deficit (mmol/L) & $-4.9(4.7)$ & $0.01(3.9)$ & $-0.84(3.1)$ \\
Lowest arterial pH & $7.34(0.09)$ & $7.34(0.07)$ & $7.34(0.07)$ \\
Highest plasma lactate (mmol/L) & $4.0(3.9)$ & $5.5(2.8)$ & $2.5(2.0)$ \\
Highest creatinine ( $\mu$ mol/L) & $65.8(24.9)$ & $59.6(19.4)$ & $77.2(30.7)$ \\
Highest oxygenation index & $14.9(18.8)$ & $7.4(4.0)$ & $5.3(3.3)$ \\
Preoperative balloon septostomy & $49(55.7 \%)$ & & \\
Duration of ventilation (d) & $4.8(4.5)$ & & $5.7(8.7)$ \\
Overall duration of hospitalization (d) & $1(1.1 \%)$ & $0(0 \%)$ & $26.8(22.7)$ \\
Clinical convulsions, yes & $2(2.3 \%)$ & $3(3.4 \%)$ & $3(3.4 \%)$ \\
Cardiopulmonary resuscitation, yes & & & $1(1.1 \%)$ \\
Dialysis used & & & $7(8.0 \%)$ \\
ECMO used & & $4(4.5 \%)$ \\
\hline
\end{tabular}

ECMO, Extracorporeal membrane oxygenation. *Prospectively collected variables at our institution.

Neurodevelopmental assessment was completed for 85 children; 2 were lost to follow-up. Three postdischarge neurologic diagnoses were unrelated to surgery: 2 cases of autism spectrum disorder and 1 case of meningitis/encephalitis. These 3 patients with mental and/or motor delay were censored from the final analysis.

For the remaining 82 patients, the mean MDI was $89 \pm$ 17 (range: 49-118) and the mean PDI was $92 \pm 15$ (range: 49-125), with no difference among the surgical groups (Figures 1 and 2). There was no difference between the scores of those born in and out of region: MDI (both $89 \pm$ 17), PDI ( $91 \pm 14,93 \pm 15$, respectively). The distribution of MDI and PDI for the whole cohort followed a leftskewed bell-shaped curve with the majority of children (66\% MDI, 71\% PDI) within 1 SD of the mean for normative data $(100 \pm 15) .{ }^{19}$ Mental delay was 7.5 times and motor delay was 2.7 times more frequent than expected based on population norms. Mental delay occurred in 14 $(17.1 \%)$, motor delay occurred in $5(6.1 \%)$, and mental and/or motor delay occurred in 15 of the 82 survivors (18.3\%). Of the 40 survivors from this region, 9 (22.5\%) were delayed, all with mental delay and 2 with motor delay. Of 4 survivors after cardiopulmonary resuscitation, 2 had mental delay and 1 had motor delay. Of 3 survivors after ECMO, 2 had mental delay and 1 had motor delay. No child had sensorineural hearing loss, epilepsy, or hydrocephalus. One child had cerebral palsy (Table 3). The overall health status of the children was acceptable, although some measures (eg, rehospitalization, need for pacemaker, and poor growth) occurred more frequently than expected for a population of children of this age (Table 3 ).
After Bonferroni correction there were no differences between delayed and nondelayed children on operative variables (Table E1). Before correction, scores for lowest mean arterial pressure for more than 10 minutes on CPB were lower for delayed children $(17.1 \% \pm 5.6 \%$ vs $21.6 \% \pm$ $6.3 \%, t=2.429, P=.017)$. Univariate correlations indicate that only a few of the potentially predictive variables have any significant relation to developmental outcome for both all assessed and those from in region (Table 4). Stepwise multiple regression for 82 children was used to determine which of those variables found significant on univariate analysis in Table 4 combine to predict overall outcome. Variables predicting MDI were total days in hospital (adjusted $\left.\mathrm{R}^{2}=0.307\right)$ and preoperative highest plasma lactate (combined adjusted $\left.R^{2}=0.395\right)$. Those predicting PDI were total days ventilated (adjusted $\mathrm{R}^{2}=0.205$ ) and duration of preoperative ventilation (combined adjusted $\mathrm{R}^{2}=0.281$ ).

Because the overall days in hospital are linked to adverse outcome, variables correlating with longer hospitalization were as follows: lower birth gestation, $\mathrm{r}=-0.536, P=$ .000 ; longer CPB time, $\mathrm{r}=0.336, P=.022$; crossclamp time, $\mathrm{r}=0.359, P=.001$; highest day 1 plasma lactate, $\mathrm{r}=$ $0.444, P=.000$; after day 1 base deficit, $\mathrm{r}=-0.277, P=$ .012 ; after day 1 dopamine use, $\mathrm{r}=0.244, P=.029$; and overall days ventilated, $\mathrm{r}=0.574, P=.000$.

Classification of variables linked to mental and/or motor delay was determined by time periods showing an overall correct classification of $92.7 \%$ for the 15 delayed of 82 assessed children and $92.5 \%$ for the subgroup from within the region with 9 delayed of 40 survivors (Table 5). 


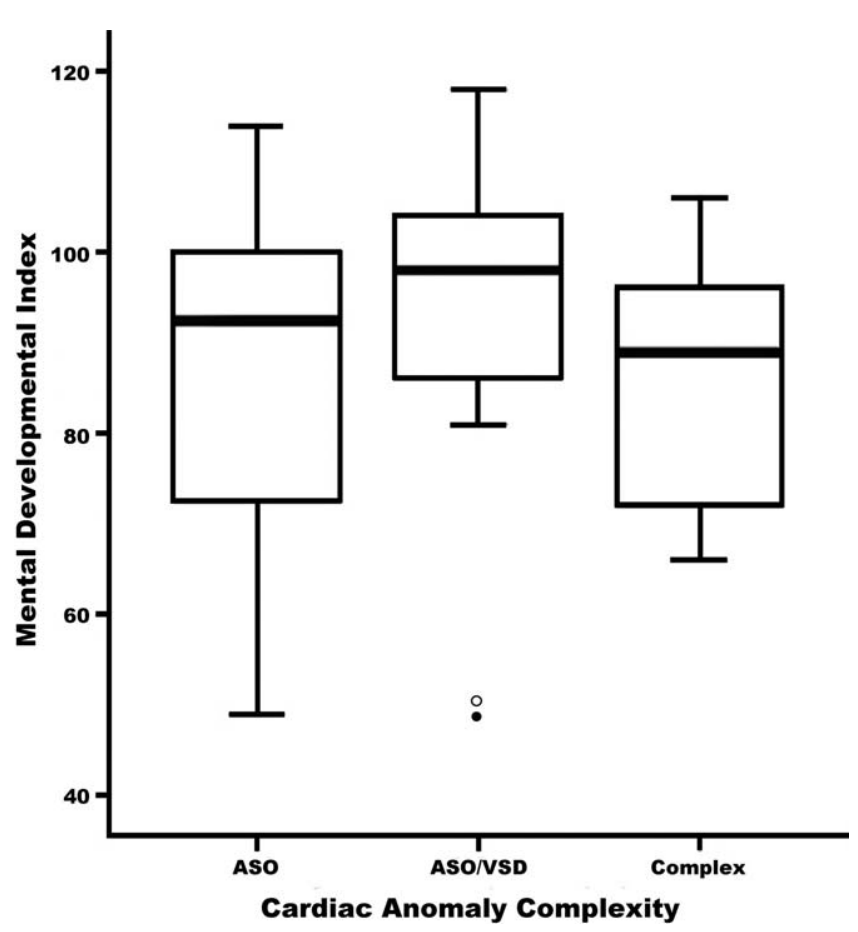

Figure 1. MDI at 18 to 24 months of age for 82 children after ASO in relation to cardiac anomaly complexity. Y-axis shows index scores. X-axis shows surgery subtypes: ASO ( $n=48$ ), ASO/VSD ( $n=21$ ), complex ( $n=13$ ). Outliers are shown as in-born (born within this region) (black circles) and out-born (born out of region and referred) (open circles). ASO, Isolated arterial switch operation; ASO/VSD, ASO with ventricular septal defect repair.

\section{Discussion}

The operative results of these 88 consecutive patients undergoing the ASO for TGA are in line with expected results for high-volume centers. ${ }^{2-4}$ The event-free survival for patients with or without VSD at an average 4-year follow-up is encouraging, with most reintervention for pulmonary valve or artery indications. Patients with more complex anatomy required more interventions, although unexpectedly, anatomic complexity was not a predictor of poor operative outcomes or late neurodevelopmental outcomes. These encouraging outcomes are possible for a variety of reasons; however, they emphasize the importance of centralization of specialized surgical expertise.

The important change seen in neurodevelopmental outcomes of this cohort in contrast with earlier cohorts ${ }^{1,7,20}$ is the improvement in motor skills. In our cohort, 1 of 82 children $(1.2 \%)$ had cerebral palsy in contrast with 7 children $(5 \%)$ in the early outcome report from Boston ${ }^{7}$ and 4 children $(5.2 \%)$ from Germany. ${ }^{20}$ Overall, 5 of $82(6.1 \%)$ of our cohort had motor skills more than 2 SD below the mean. The Boston study showed 28 of $142(20 \%)$ with delay ${ }^{7}$ $(\leq 80)$ on motor tasks, and the study from Germany ${ }^{20}$

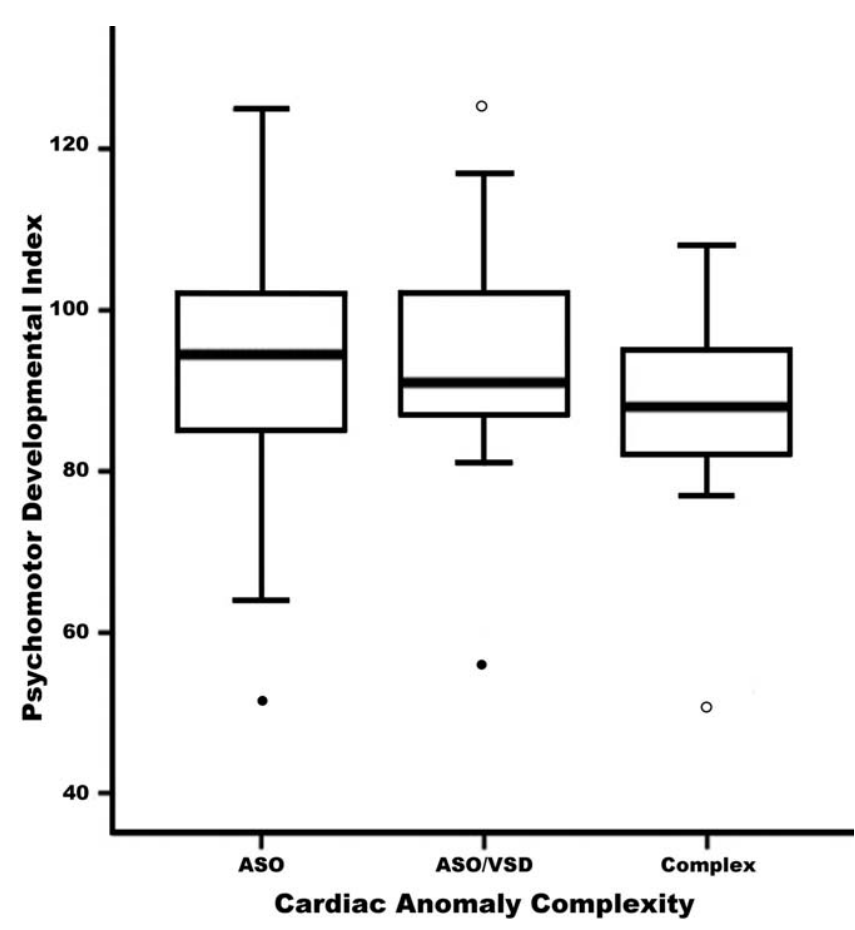

Figure 2. PDI at 18 to 24 months of age for 82 children after ASO in relation to cardiac anomaly complexity. Y-axis shows index scores. X-axis shows surgery subtypes: ASO (n = 48), ASO/VSD ( $n=21)$, complex $(n=13)$. Outliers are shown as in-born (born within this region) (black circles) and out-born (born out of region and referred) (open circles). ASO, Isolated arterial switch operation; ASO/VSD, ASO with ventricular septal defect repair.

showed $22.1 \%$ with delay of 2 SD or more for fine motor skills and $23.4 \%$ for gross motor skills. This improvement in motor skills may reflect evolving changes in operative and perioperative management. This change in treatment may be, in part, why our children with VSD do not have scores lower than those without VSD as has been reported. ${ }^{7}$ DHCA was used in only 3 of the 22 children with VSD in this study.

Long-term outcome studies suggest cognitive scores after TGA repair remain slightly below those from population normative data and peers. ${ }^{1,10,11}$ Although within normal limits, the mean mental score in this series is 11 points below normative data. Our addition of subjects with complex lesions, not found in the other series, does not seem to be the reason for these lower mental scores. Socioeconomic status was unrelated to outcome. The excess developmental delay persisted despite exclusion of 3 children with unrelated conditions. The occurrence of 2 children with autism spectrum disorder may reflect the increasing frequency of diagnosis of this disorder in recent years. ${ }^{21}$ The Bayley Scales of Infant Development are developmental in nature, not an intelligence test. There has been concern that assess- 
TABLE 3. Early childhood health and growth after arterial switch operation in relation to complexity of cardiac anomaly ( $\mathrm{n}=\mathbf{8 2}$ )

\begin{tabular}{|c|c|c|c|c|c|c|}
\hline & $\begin{array}{c}\text { Total } \\
\mathrm{n}=82\end{array}$ & $\begin{array}{c}\text { ASO } \\
n=48\end{array}$ & $\begin{array}{c}\text { ASO/VSD } \\
n=21\end{array}$ & $\begin{array}{c}\text { Complex } \\
n=13\end{array}$ & $x^{2}$ & $P^{*}$ \\
\hline Length $<3$ rd percentile & $8(9.8 \%)$ & $3(6.3 \%)$ & $3(14.3 \%)$ & $2(15.4 \%)$ & 1.627 & .443 \\
\hline Weight $<3$ rd percentile & $5(6.1 \%)$ & $2(4.2 \%)$ & $1(4.8 \%)$ & $2(15.4 \%)$ & 2.336 & .311 \\
\hline Microcephaly & $1(1.5 \%)$ & $1(2.1 \%)$ & $0(0 \%)$ & $0(0 \%)$ & 0.846 & .655 \\
\hline Current nutritional supplement & $3(3.7 \%)$ & $1(2.1 \%)$ & $0(0 \%)$ & $2(15.4 \%)$ & 6.207 & .045 \\
\hline Hospitalization after initial discharge & $22(26.8 \%)$ & $12(25.0 \%)$ & $3(14.3 \%)$ & $7(53.8 \%)$ & 6.599 & .037 \\
\hline$>2$ hospitalizations & 2 & 1 & 1 & 0 & Not computed & \\
\hline Current medication for lung disease & $7(8.8 \%)$ & $5(10.6 \%)$ & $0(0 \%)$ & $2(15.4 \%)$ & 2.844 & .241 \\
\hline Abnormal respiratory examination result & $8(10.1 \%)$ & $2(4.3 \%)$ & $2(9.5 \%)$ & $4(33.3 \%)$ & 8.797 & .012 \\
\hline Current medication for heart disease & $4(4.9 \%)$ & $2(2.1 \%)$ & $2(10.0 \%)$ & $1(7.7 \%)$ & 2.135 & .344 \\
\hline Permanent pacemaker & $4(4.9 \%)$ & $2(4.2 \%) \dagger$ & $2(9.5 \%) \ddagger$ & $0(0 \%)$ & 1.696 & .428 \\
\hline Visual impairment $(<20 / 60)$ & $1(1.2 \%)$ & $0(0 \%)$ & $0(0 \%)$ & $1(7.7 \%) \S$ & 5.373 & .068 \\
\hline Cerebral palsy & $1(1.2 \%)$ & $0(0 \%)$ & $0(0 \%)$ & $1(7.7 \%) \|$ & 5.373 & .068 \\
\hline Strabismus & $4(5.8 \%)$ & $1(2.1 \%)$ & $0(0 \%)$ & $3(23.1 \%)$ & 13.833 & .086 \\
\hline
\end{tabular}

ASO, Isolated arterial switch operation; $A S O / V S D$, arterial switch operation with ventricular septal defect repair; After Bonferroni correction, $P$ values of .004 or less remain significant. *Chi-square analysis. †One with sinus node dysfunction secondary to stenting of the superior vena cava, one with dysrhythmia now in sinus rhythm. ¥Two with complete heart block, one of whom is now mostly in sinus rhythm. $\$ 0$ cular albinism. \|Spastic ambulatory cerebral palsy and preoperative thrombosis.

ment of 1-year mental and motor development may correlate only modestly with performance later in life. ${ }^{22}$ Our study agrees with other reports that identify these children as "at risk" for developmental difficulties with the potential for future poor performance. . $^{1,10,20,22}$

Research into the developmental outcomes of neonates undergoing heart surgery has resulted in changes to the conduct of the surgery; DHCA and low-flow CPB have been changed in favor of full-flow CPB with a short period of arrest for closure of the atrial septal defect and VSD. Although half of our patients underwent a period of DHCA, there was no difference in the use of DHCA or the length of DHCA time between those with and without developmental delay. Thus, this select DHCA was not a predictor of developmental delay. This is in contrast with other published reports, ${ }^{8,9}$ possibly because our DHCA times averaged less than the 41-minute cutoff suggested by others. ${ }^{9}$ Although we expected poorer developmental outcomes in Group C, anatomic complexity was not a predictor of poor outcome. This has to be interpreted cautiously because of the small sample size. The majority of complex arch repairs are presently performed under deep hypothermia with continuous perfusion through the right innominate artery and continuous near-infrared spectrometry monitoring of cerebral oximetry.

To improve outcomes further, one might expect antenatal diagnosis, delivery in the treating institution, immediate admission to the neonatal intensive care unit, and expeditious definitive surgical repair would be the ideal situation. We did not have sufficient numbers (7/88 were diagnosed antenatally) to examine the influence of antenatal diagnosis on ultimate outcomes. Although early results have been disappointing, this approach remains an area of possible positive change. Our study suggests possible improvements in neurodevelopmental outcomes for neonates with TGA may be made preoperatively. Lower gestational age, days ventilated, and highest preoperative lactate are surrogates for the child's overall preoperative status. The latter 2 support previous concerns about preoperative acidosis. ${ }^{1,11}$ Stepwise multiple regression shows highest preoperative lactate gives $8.8 \%$ of the variance of mental outcome of the entire cohort. There is no suggestion of selection bias in favor of out-ofregion children affecting the use of preoperative lactate as a predictor. In this study, specificity for prediction of better outcome is excellent (97\%) for the preoperative period if the babies are term and lactate levels are low. As hospitalization continues, other factors increase the sensitivity for adverse outcome, but add only $8.6 \%$ to the overall classification. The lowest mean arterial pressure for more than 10 minutes on CPB adds $2.5 \%$ to the correct classification and increases sensitivity by $13.3 \%$. This requires further study. Duration of hospitalization has been shown to be a predictor of adverse outcome ${ }^{23}$ and links to adverse outcome in this study. However, prolonged stay reflects earlier/other variables and in isolation does not address changes that can be made to improve care.

Plasma lactate has been found to be an early marker of mortality after pediatric cardiac surgery,${ }^{24}$ although the positive predictive value has not been high. ${ }^{25}$ Recently we showed the value of postoperative serial lactate determination to predict survival and help to differentiate intact survival in a cross-sectional population after open surgery at 
TABLE 4. Two-tailed Pearson product-moment correlations $(r)$ with $\boldsymbol{P}$ values of significant $(<.05)$ predictor variables in relation to developmental indices for 82 survivors after the arterial switch operation and those only from within region $(n=40)$

\begin{tabular}{|c|c|c|c|c|c|c|c|c|}
\hline \multirow[b]{3}{*}{ Predictor variables } & \multicolumn{4}{|c|}{ All assessed $(n=82)$} & \multicolumn{4}{|c|}{ Assessed from within region $(n=40)$} \\
\hline & \multicolumn{2}{|c|}{ MDI } & \multicolumn{2}{|c|}{ PDI } & \multicolumn{2}{|c|}{ MDI } & \multicolumn{2}{|c|}{ PDI } \\
\hline & $\mathbf{r}$ & $P$ & $\mathbf{r}$ & $\boldsymbol{P}$ & $\mathbf{r}$ & $P$ & $\mathbf{r}$ & $\boldsymbol{P}$ \\
\hline \multicolumn{9}{|l|}{ Preoperative } \\
\hline Gestational age (wk) & 0.312 & .004 & 0.321 & .003 & 0.323 & .042 & 0.405 & .009 \\
\hline Duration of ventilation (d) & - & - & -0.351 & .001 & -0.333 & .036 & - & - \\
\hline Highest plasma lactate $(\mathrm{mmol} / \mathrm{L})$ & -0.265 & .016 & - & - & -0.336 & .034 & - & - \\
\hline \multicolumn{9}{|l|}{ Operative } \\
\hline $\begin{array}{l}\text { Lowest mean arterial pressure for }>10 \text { min on } \\
\text { CPB }(\mathrm{mm} \mathrm{Hg})\end{array}$ & - & - & - & - & 0.415 & .008 & - & - \\
\hline \multicolumn{9}{|l|}{ Postoperative, first $24 \mathrm{~h}$} \\
\hline Highest plasma lactate (mmol/L) & -0.254 & .021 & -0.220 & .048 & -0.514 & .001 & -0.307 & .049 \\
\hline Lowest base deficit (mmol/L) & 0.220 & .047 & - & - & - & - & - & - \\
\hline Highest creatinine ( $\mu \mathrm{mol} / \mathrm{L})$ & - & - & -0.263 & .017 & - & - & - & - \\
\hline \multicolumn{9}{|l|}{ Postoperative, after $24 \mathrm{~h}$} \\
\hline Highest plasma lactate (mmol/L) & -0.257 & .020 & - & - & - & - & - & - \\
\hline Lowest base deficit (mmol/L) & 0.250 & .024 & 0.226 & .041 & - & - & - & - \\
\hline Lowest arterial pH & - & - & 0.271 & .014 & - & - & - & - \\
\hline Highest oxygenation index & -0.248 & .024 & -0.296 & .007 & - & - & -0.378 & .018 \\
\hline Highest creatinine $(\mu \mathrm{mol} / \mathrm{L})$ & - & - & -0.219 & .048 & - & - & - & - \\
\hline Epinephrine used & -0.232 & .036 & - & - & - & - & - & - \\
\hline \multicolumn{9}{|l|}{ Overall days } \\
\hline Duration of ventilation (d) & -0.480 & .000 & -0.460 & .000 & -0.522 & .001 & -0.436 & .005 \\
\hline Duration of hospitalization at this institution (d) & -0.512 & .000 & -0.315 & .000 & -0.570 & .000 & -0.465 & .003 \\
\hline
\end{tabular}

$M D I$, Mental Developmental Index; PDI, Psychomotor Development Index; $C P B$, cardiopulmonary bypass. Variables that had no significant correlation with either MDI or PDI for all assessed or those assessed from this region are not listed but were preoperative data of age at surgery, 5-minute Apgar score, birth weight, gender, antenatal diagnosis, socioeconomic index, lowest $\mathrm{PAO}_{2}$, base deficit, arterial $\mathrm{pH}$, highest creatinine, oxygenation index and dopamine given, epinephrine given; operative data of CPB time, lowest flow for $>10 \mathrm{~min}$, lowest temperature for all and those receiving circulatory arrest, circulatory arrest, re-CPB in operating room; day 1 lowest $\mathrm{PAO}_{2}$ and arterial $\mathrm{pH}$, highest oxygenation index and dopamine given, epinephrine used; beyond day 1 , lowest $\mathrm{PAO}_{2}$.

6 weeks or less of age. ${ }^{16}$ This study shows the continued correlation of early postoperative lactate and developmental delay, and the predictive value of preoperative lactate. In light of these findings, it will be important to explore what factors associated with high lactate may be modifiable in an attempt to improve neurodevelopmental outcomes.

Our study is limited by the relatively short follow-up period. Although we did not observe a significant rate of late

TABLE 5. Classification of combined variables found significantly related to early childhood mental and/or motor neurodevelopmental delay after neonatal arterial switch operation*

\begin{tabular}{|c|c|c|c|c|c|c|}
\hline Step & Added variable & Sensitivity & Specificity & PPV & NPV & $\begin{array}{c}\text { Percentage correctly } \\
\text { classified }\end{array}$ \\
\hline \multicolumn{7}{|c|}{ A. For all 82 assessed with 15 delayed children } \\
\hline 1 & Preoperative gestational age (wk) plasma lactate (mmol/L) & $26.7 \%$ & $97.0 \%$ & $67.0 \%$ & $85.5 \%$ & $84.1 \%$ \\
\hline 2 & Operative lowest mean MAP on CPB for $>10 \mathrm{~min}(\mathrm{~mm} \mathrm{Hg})$ & $40.0 \%$ & $97.0 \%$ & $75.0 \%$ & $87.8 \%$ & $86.6 \%$ \\
\hline 3 & Overall days ventilated & $60.0 \%$ & $97.0 \%$ & $81.8 \%$ & $91.5 \%$ & $90.2 \%$ \\
\hline 4 & Overall days in hospital & $73.3 \%$ & $97.0 \%$ & $84.6 \%$ & $94.2 \%$ & $92.7 \%$ \\
\hline \multicolumn{7}{|c|}{ B. For 40 from within region with 9 delayed children } \\
\hline 1 & Preoperative plasma lactate $(\mathrm{mmol} / \mathrm{L})$ days ventilated & $44.4 \%$ & $100.0 \%$ & $100 \%$ & $86.1 \%$ & $87.5 \%$ \\
\hline 2 & Overall days in hospital & $79.8 \%$ & $96.8 \%$ & $87.5 \%$ & $93.8 \%$ & $92.5 \%$ \\
\hline
\end{tabular}

PPV, Positive predictive value; $N P V$, negative predictive value; $M A P$, mean arterial pressure; $C P B$, cardiopulmonary bypass. *Variables found to have significant correction with outcome (Table 4) were entered; all that were not additive were not included. 
aortic root complications, stenosis or insufficiency of both pulmonary and aortic valves can occur beyond our average follow-up of 4 years. ${ }^{26}$ The numbers of patients in our individual groups were small; thus subtle differences in operative and late outcomes may have been overlooked. Although neonatal seizures have been linked to poor outcome, ${ }^{27}$ we clinically identified 1 child with preoperative seizures and 3 children with postoperative seizures, with 1 of the latter developmentally delayed. Because this study did not perform routine cranial imaging and electroencephalography it is likely that neurologic events including seizures were underestimated. ${ }^{13}$

\section{Conclusions}

TGA in the current era can be corrected with excellent operative and long-term survival. Reintervention rates are low, although higher in complex cases. Compared with published reports, this study shows a reduction in the prevalence of cerebral palsy and in motor delay. Neurodevelopmental mental status remains a concern. We have shown that preoperative status contributes significantly to late outcomes. Optimizing patient status and subsequent expeditious surgical correction may be paramount for further improving outcomes.

We are indebted to the parents of the ill children for their positive cooperation with this follow-up program. We thank Dr. Donald Schopflocher, Biostatistician, Edmonton, Alberta, for his statistical review of this article. We thank the research coordinators who made this research study possible: $\mathrm{H}$. Christianson and D. Anseuw-Deeks, Calgary, Alberta; V. Debooy, Winnipeg, Manitoba; S. Selzer, Regina, Saskatchewan; T. Martindale, Saskatoon, Saskatchewan; G. Alton and L. Sanders, Edmonton, Alberta.

\section{References}

1. Karl TR, Hall S, Ford G, Kelly EA, Brizard CPR, Mee RBB, et al Arterial switch with full-flow cardiopulmonary bypass and limited circulatory arrest: neurodevelopmental outcome. J Thorac Cardiovasc Surg. 2004;127:213-22.

2. Duncan BW, Poirier NC, Mee RB, Drummond-Webb JJ, Qureshi A, Mesia CI, et al. Selective timing for the arterial switch operation. Ann Thorac Surg. 2004;77:1691-6.

3. DiBardino DJ, Allison AE, Vaughn WK, McKenzie ED, Fraser CD Jr. Current expectations for newborns undergoing the arterial switch operation. Ann Surg. 2004;239:588-96.

4. Hutter PA, Kreb DL, Mantel SF, Hitchcock JF, Meijboom EJ, Bennink GB. Twenty-five years' experience with the arterial switch operation. J Thorac Cardiovasc Surg. 2002;124:790-7.

5. Losay J, Touchot A, Serraf A, Litvinova A, Lambert V, Piot JD, et al Late outcome after arterial switch operation for transposition of the great arteries. Circulation. 2001;18;104(12 Suppl 1):I121-I6.

6. Ungerleider RM, Gaynor JW. The Boston Circulatory Arrest Study: an analysis. J Thorac Cardiovasc Surg. 2004;127:1256-61.

7. Bellinger DC, Jonas RA, Rappaport LA, Wypij D, Wernovsky G, Kuban KC, et al. Developmental and neurologic status of children after heart surgery with hypothermic circulatory arrest or low-flow cardiopulmonary bypass. $N$ Engl J Med. 1995;2;332:549-55.
8. Bellinger DC, Wypij D, Kuban KC, Rappaport LA, Hickey PR, Wernovsky G, et al. Developmental and neurological status of children at 4 years of age after heart surgery with hypothermic circulatory arrest or low-flow cardiopulmonary bypass. Circulation. 1999;3;100:526-32.

9. Wypij D, Newburger JW, Rappaport LA, duPlessis AJ, Jonas RA, Wernovsky G, et al. The effect of duration of deep hypothermic circulatory arrest in infant heart surgery on late neurodevelopment: the Boston Circulatory Arrest Trial. J Thorac Cardiovasc Surg. 2003; 126:1397-403.

10. Bellinger DC, Wypij D, duDuplessis AJ, Rappaport LA, Jonas RA, Wernovsky G, et al. Neurodevelopmental status at eight years in children with dextro-transposition of the great arteries: the Boston Circulatory Arrest Trial. J Thorac Cardiovasc Surg. 2003;126:1385-96.

11. Hovels-Gurich HH, Seghaye MC, Schnitker R, Wiesner M, Huber W, Minkenberg R, et al. Long-term neurodevelopmental outcomes in school-aged children after neonatal arterial switch operation. J Thorac Cardiovasc Surg. 2002;124:448-58.

12. Robertson CM, Joffe AR, Sauve RS, Rebeyka IM, Phillipos EZ, Harder JR, et al. Outcomes from an interprovincial program of newborn open heart surgery. J Pediatr. 2004;144:86-92.

13. Miller SP, McQuillen PS, Vigneron DB, Glidden DV, Barkovich AJ, Ferriero DM, et al. Preoperative brain injury in newborns with transposition of the great arteries. Ann Thorac Surg. 2004;77:1698-706.

14. Bartlett JM, Wypij D, Bellinger DC, Rappaport LA, Heffner LJ, Jonas RA, et al. Effect of prenatal diagnosis on outcomes in D-transposition of the great arteries. Pediatrics. 2004;113:e335-e40.

15. Newburger JW, Wypij D, Berlinger DC, Du Plessis AJ, Kubon KCK, Rappaport LA, et al. Length of stay after infant heart surgery in relation to cognitive outcome at age 8 years. J Pediatr. 2003;143:67-73.

16. Cheung PY, Chui N, Joffe AR, Rebeyka IM, Robertson CM. Postoperative lactate concentrations predict the outcome of infants aged 6 weeks or less after intracardiac surgery: a cohort follow-up to 18 months. J Thorac Cardiovasc Surg. 2005;130:837-43.

17. Blishen BR. The 1981 Socioeconomic Index for Occupations in Canada. Canad Rev Soc Anth. 1987;24:465-88.

18. Bax MC. Terminology and classification of cerebral palsy. Dev Med Child Neurol. 1964;11:295-7.

19. Bayley N. Manual: Bayley Scales of Infant Development. 2nd ed. San Antonio: Psychological Corp; 1993.

20. Hovels-Gurich HH, Seghaye MC, Dabritz S, Messmer BJ, von Bernuth G. Cognitive and motor development in preschool and schoolaged children after neonatal arterial switch operation. J Thorac Cardiovasc Surg. 1997;114:578-85.

21. Larsson HJ, Eaton WW, Madsen KM, Vestergaard M, Olesen AV, Agerbo E, et al. Risk factors for autism: perinatal factors, parental psychiatric history, and socioeconomic status. Am J Epidemiol. 2005; 161:916-25.

22. McGrath E, Wypij D, Rappaport LA, Newburger JW, Bellinger DC Prediction of IQ and achievement at age 8 years from neurodevelopmental status at age 1 year in children with D-transposition of the great arteries. Pediatrics. 2004;114:e572-e6.

23. Newburger JW, Wypij D, Berlinger CD, du Plessie AJ, Kubon KCK, Rappaport LA, et al. Length of stay after infant heart surgery is related to cognitive outcome at 8 years. J Pediatr. 2003;143:67-73.

24. Duke T, Butt W, South M, Karl TR. Early markers of major adverse events in children after cardiac operations. J Thorac Cardiovasc Surg. 1997; 114:1042-52.

25. Hatherill M, Sajjanhar T, Tibby SM, Champion MP, Anderson D, Marsh MJ, et al. Serum lactate as a predictor of mortality after paediatric cardiac surgery. Arch Dis Child. 1997;77:235-8.

26. Schwartz ML, Gauvreau K, del Nido P, Mayer JE, Colan SD. Longterm predictors of aortic root dilation and aortic regurgitation after arterial switch operation. Circulation. 2004;110(11 Suppl 1):II128II132.

27. Rappaport LA, Wypij D, Bellinger DC, Helmers SL, Holms GL, Bernes PD, et al. Relation of seizures after cardiac surgery in early infancy to neurodevelopmental outcome. Circulation. 1998;97:73-9. 
A. Overall Survival

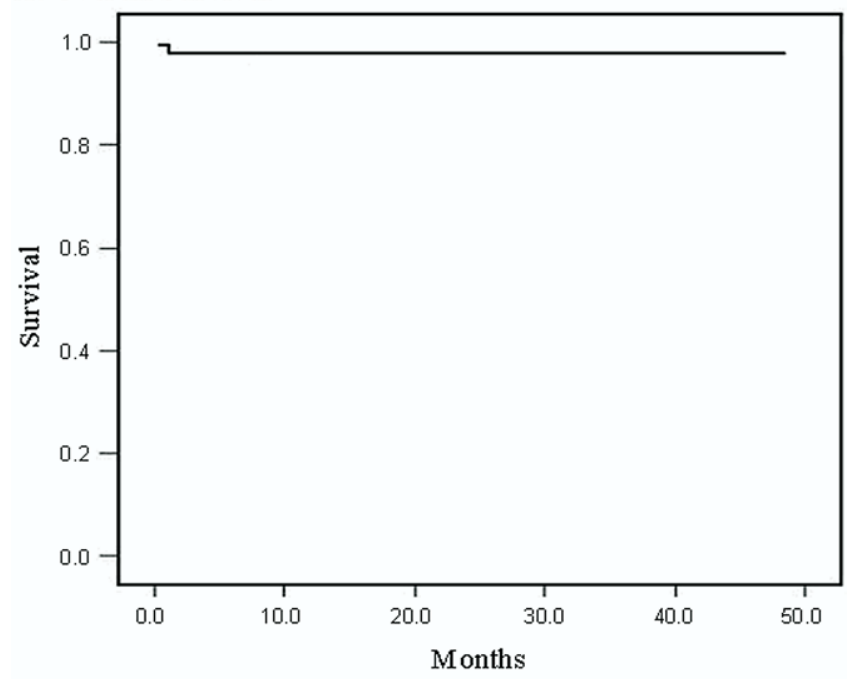

B. Event Free Survival

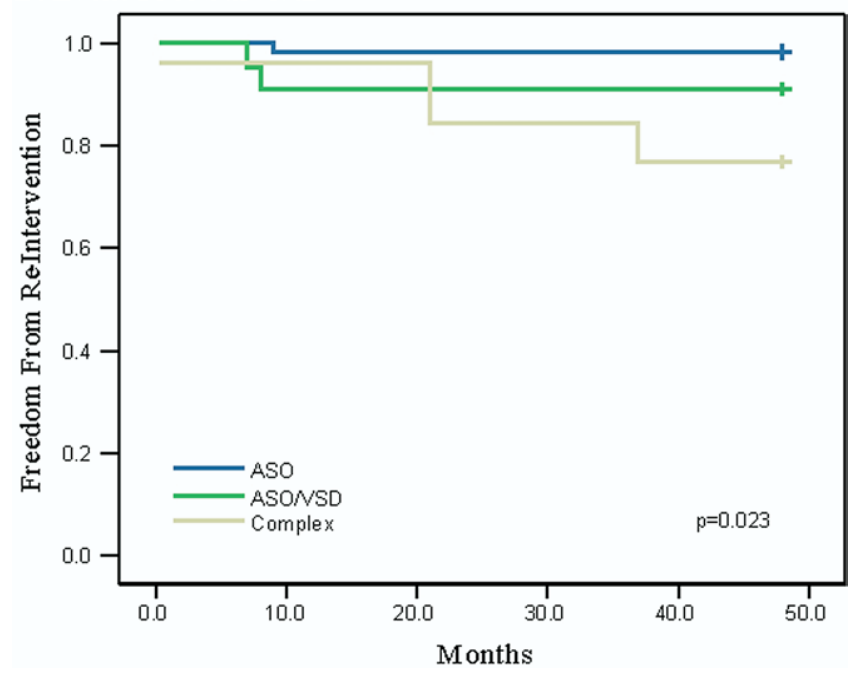

Figure E1. Unadjusted Kaplan-Meier survival curves for all 88 patients after the neonatal ASO. ASO, Isolated arterial switch operation; ASO/VSD, ASO with ventricular septal defect repair. 
TABLE E1. Intraoperative variables during arterial switch operation in relation to mental and/or motor delay among 82 children at 18 to 24 months: Mean (standard deviation), n (\%)

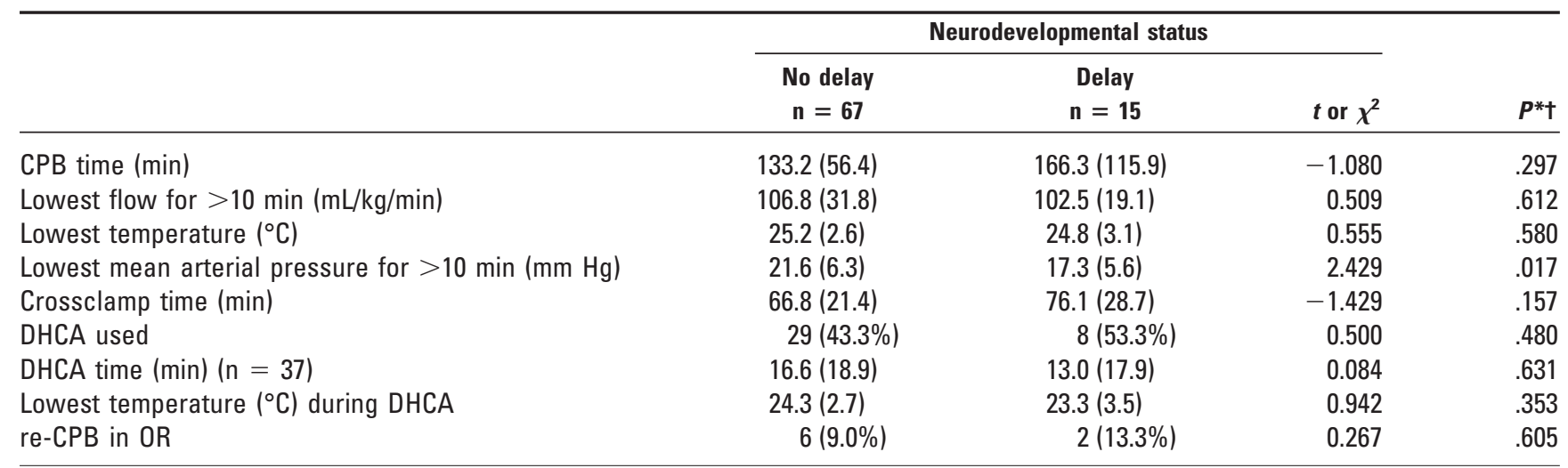

$\overline{D H C A}$, Deep hypothermia and circulatory arrest; $C P B$, cardiopulmonary bypass; $O R$, operating room. After Bonferroni correction, $P$ values of .006 or less remain significant. *Two-tailed $t$ test, reported after correction (Levene's test of equality of variances). $†$ Chi-square analysis. 